\title{
VALORIZATION AND RECYCLING OF QUARRIES WASTE AS AN ADDITION IN CEMENT
}

\author{
Said Berdoudi* \\ National Polytechnic School of Algiers, Hacen Badi Elharrach, Algeria \\ H.Hebhoub \\ University of Skikda, Skikda, Algeria \\ R.Djebien \\ University of Skikda, Skikda, Algeria
}

The management of mining waste is one of the major environmental problems which are facing the mining professionals, during their activity and even after the closure of the mine. Indeed, excavated materials from mines belong to a category of waste, and especially when dealing with an open pit, are generally left on the surface. In this experimental study, the utilization of sand waste marble dust as an additive in cement production has been investigated. The aggregate used in this study is a sand of marble wastes (excess loads of sand exposed to bad weather conditions) of the derived marble quarry from Fil-fila (Skikda, east of Algeria). The study focuses the effect of marble waste sand fillers substitution in the cement paste and mortar (5, 10, 15 and 20\%) with a finesse greater than that of cement, to compare the results obtained through control samples (0\%) of cement paste properties in the fresh condition and the mechanical performances of mortar in the hardened condition. The obtained results show that the sand marble wastes fillers can be technically used as additive in cement. Therefore, it can be possible to prevent the environmental pollution especially in this region with excessive marble production and to well manage natural resources.

Key words: Wastes, Sand; Mining; Marble; Fillers; Cementation; Additives

\section{INTRODUCTION}

Waste management is currently one of the major encountered problems especially in developing countries. Our study is registered in a politic of recycling and valorizing of wastes that can be used in the cement formulation. According to Amritpal and Rajwinder, (2015) [01] the consumption of cement and cost are more and more increasing, blended cement based on the partial replacement of Portland cement clinker by wastes has been recently the object of many investigations (Gurumoorthy, 2014) [07]. Corinaldesi and al, (2010) [6] reported that marble waste, consisting of very fine particles, was one of the environmental problems around the world. However this marble dust can be used either to produce new products or as an admixture so that the natural sources are used more efficiently and the environment will be saved properly (Hameed and Sekar, 2009) [08]. Many studies have shown the importance of using these wastes, Hebhoub et al (2013) [10] have recently used this type of waste as sand introduced in mortars. Using marble waste in hydraulic concrete and mortars were also studied by evaluating their fresh and hardened state properties (Hebhoub and al (2011), Aruntas and al (2010), Belaidi and al, (2012)) [9, 2, 3]. The world preoccupation aims firstly at reducing the cost of cement and secondly the environment's impact, Therefore, construction industry is seeking to other alternatives in order to meet the needs of cement manufacturing as it was demonstrated by Niyazi ugri, (2013) [13]. We are so interested in making a cement CEM II from a cement CEM I by adding fillers of marble waste sand (marble powder exposed to bad weather conditions). In this study we recover and introduce this type of marble (marble waste sand) from the quarry of Fil-fila as substitute filler in cement, the deposit is located in $25 \mathrm{~km}$ in the eastern side of Skikda city, Algeria. 


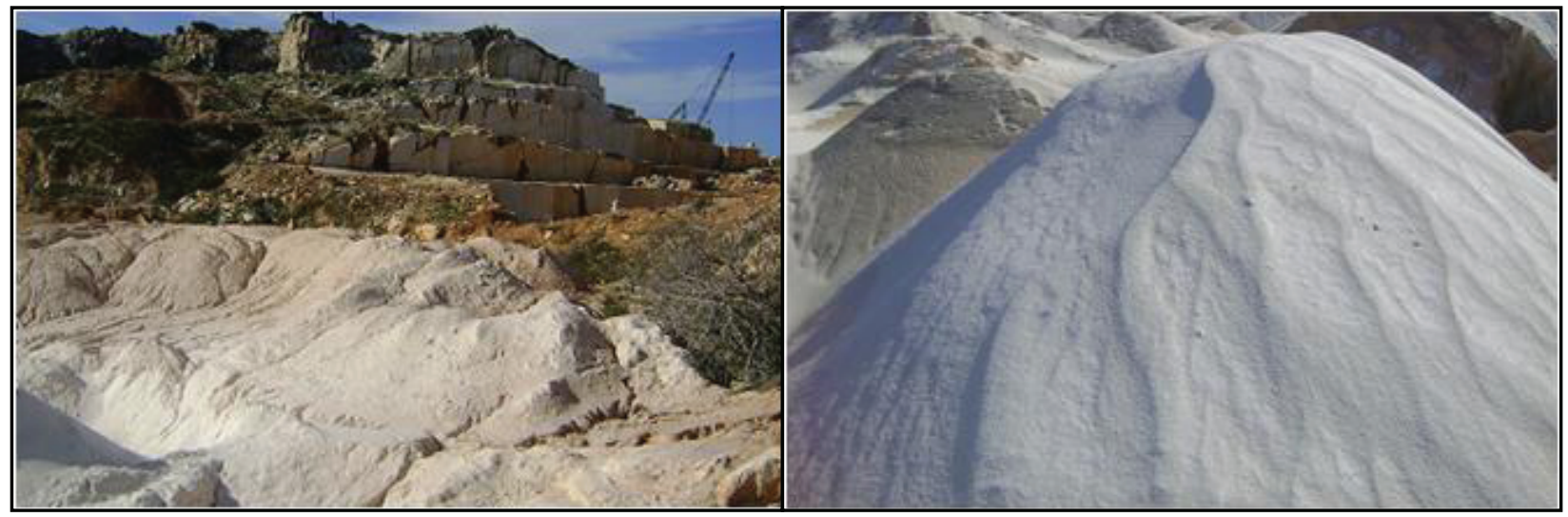

Figure1: Marble powder exposed to bad weather conditions of Fil-fila quarry (Algeria)

\section{CHARACTERIZATIONS OF THE USED MATERIALS}

The materials used, in this study, are:

- Cement CEM I class 42.5 coming from the cement works of Hdjar Soud Company (Algeria).

- Fillers of marble waste sand are obtained from the local quarry by grinding in a standard normalized ball.

- The mortars are prepared with standard sand CEN according to the norm EN 196-1, this natural siliceous sand with an apparent density of $1.63 \mathrm{~g} / \mathrm{Cm}^{3}$ and an absolute density of $2.5 \mathrm{~g} / \mathrm{Cm}^{3}$, this sand is inert from a chemical point of view with fineness module of 2.33 .

The results characterizations tests are shown in the Table 1.

According to the results listed in Table 1 and chemical analysis, the marble waste sand is limestone fillers $\left(98.67 \mathrm{C}_{\mathrm{a}} \mathrm{CO}_{3}\right)$. The addition of marble waste sand fillers in cement leads to increase the $\mathrm{CaO}$ quantity. This increase gives a lot of $\mathrm{C} 3 \mathrm{~S}$ and reduces the quantity of $\mathrm{C}_{2} \mathrm{~S}, \mathrm{C}_{3} \mathrm{~A}$ and $\mathrm{C} 4 \mathrm{AF}$.

Table 1: Results of characterizations tests

\begin{tabular}{|c|c|c|c|c|c|}
\hline Characteristics & CEM I 42.5 & $\begin{array}{l}\text { Marble wastes } \\
\text { sand fillers }\end{array}$ & Characteristics & CEM I 42.5 & $\begin{array}{c}\text { Marble wastes } \\
\text { sand fillers }\end{array}$ \\
\hline $\begin{array}{l}\text { Absolute den- } \\
\text { sity (g/cm3) }\end{array}$ & 3.33 & 2.79 & Insoluble residue & 0.85 & 0.035 \\
\hline $\begin{array}{l}\text { Specific surface } \\
\text { (Blaine) }\left(\mathrm{cm}^{2} / \mathrm{g}\right)\end{array}$ & 3200 & 6500 & $\mathrm{CaO}$ (free) & 0.4 & -- \\
\hline $\mathrm{CaO}$ & 61.31 & 55.29 & MS & 2.52 & -- \\
\hline $\mathrm{Al}_{2} \mathrm{O}_{3}$ & 5.45 & 0.14 & MAF & 1.54 & -- \\
\hline $\mathrm{Fe}_{2} \mathrm{O}_{3}$ & 3.54 & 0.09 & LSF & 0.88 & -- \\
\hline $\mathrm{SiO}_{2}$ & 22.73 & 0.53 & $\mathrm{MH}$ & 1.93 & -- \\
\hline $\mathrm{MgO}$ & 0.48 & 0.2 & $\mathrm{C}_{3} \mathrm{~S}$ & 28.14 & -- \\
\hline $\mathrm{Na}_{2} \mathrm{O}$ & 0.19 & 0.00 & $\mathrm{C}_{2} \mathrm{~S}$ & 38.71 & -- \\
\hline $\mathrm{K}_{2} \mathrm{O}$ & 0.63 & 0.01 & $\mathrm{C}_{3} \mathrm{~A}$ & 8.45 & -- \\
\hline $\mathrm{Cl}-$ & 0.035 & 0.025 & $\mathrm{C}_{4} \mathrm{AF}$ & 10.76 & -- \\
\hline $\mathrm{SO}_{3}$ & 2.44 & 0.04 & $\mathrm{CaCO}_{3}$ & - & 98.67 \\
\hline Loss on ignition & 2.45 & 43.40 & & & \\
\hline
\end{tabular}




\section{EXPERIMENTAL PROGRAM}

In the experimental program, we study the substitution of a cement part by the marble wastes sand additions, by varying the substitutions rate (0\%, 5\%,10\%, 15\%, 20\%). The work is divided into two series.

\section{Step 1:}

Manufacture starting from cement CEM I and marble wastes sand fillers a cement pastes with substitutions rates $(0 \%, 5 \%, 10 \%, 15 \%, 20 \%)$.

The constants and variables parameters are water/cement ratio which is equal to 0.27 and the substitution rate respectively. Tests made in this company are consistency, setting and steadiness.

\section{Step 2:}

Manufacture starting from cement CEM I and marble wastes sand fillers mortars with substitutions rates $(0 \%, 5 \%, 10 \%, 15 \%, 20 \%)$. The constants and variables parameters are water/cement ratio which is equal to 0.5 and sand, substitution rate respectively. Tests on hardened mortar samples are compressive, tensile strength in flexion at 2, 7, 28 and 90 days and shrinkage test at 2,7,28 days.

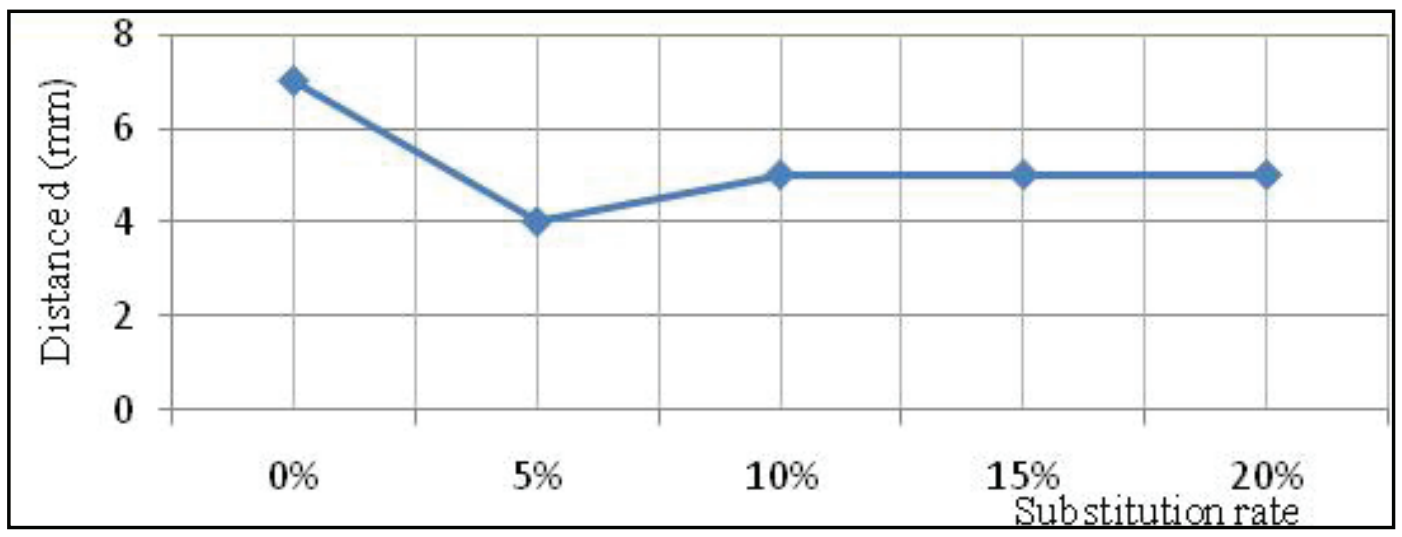

Figure 2: Variation of consistency according to the substitution rate.

\section{EFFECT OF MARBLE WASTE SAND FILLERS ON THE CEMENT PASTE CHARACTERISTICS}

\section{Consistency}

Generally, the consistency variation is weak for all mixtures. The bad consistency is obtained for the witness concrete of $0 \%$ substitution rate (cement rich in C3A) in accordance with Messan, (2006) [11], for a specific sur- face Blaine of the marble wastes higher than that of CEMI, the variation is a decreasing substitution function till 5\% where the effect reverses to stabilize between $10 \%$ and $20 \%$. As a consequent, the fillers effect is insignificant. From this perspective, Neto and Campiteli, (1990) [12] found out that the consistency of cements, containing up to $15 \%$ of limestone rich in $\mathrm{CaCO} 3$, decreased, especially for the finer cements.

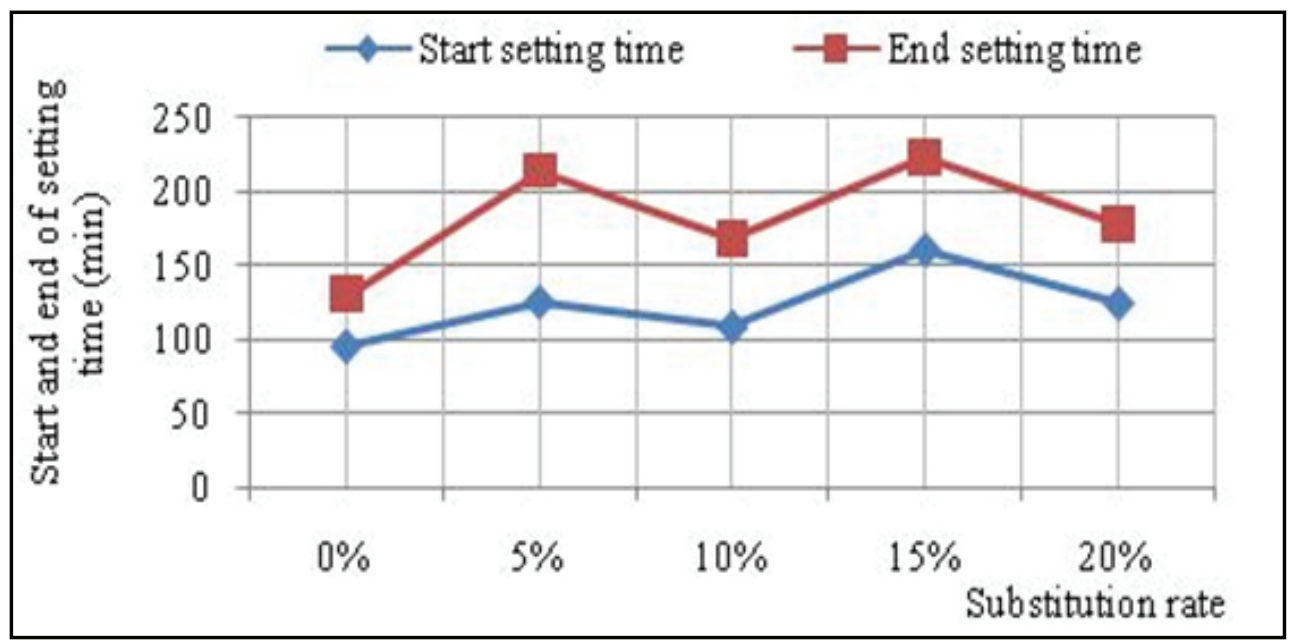

Figure 3: Variation of the start and end of setting time versus the substitution rate 


\section{Start and end of setting time}

The figure 3 gives the variation of setting time's start and end concerning the substitution rate. Vuk and al, (2001) [16] point out that the effects of clinker composition were less significant when the cement fineness was higher. In this study; the results show that the importance of the specific surface of Blaine is in a reversal relation with time. For W/C constant, the start and the end of setting time vary according to the substitution rate, the minimum values are obtained for the witness concrete (the pres- ence of a large quantity of C3A giving a fast setting) as it was proved by Messan, (2006) [11]. The maximal values are obtained for a substitution rate of $15 \%$ of the marble wastes fillers.

\section{Steadiness}

The hydration reaction is accelerated by a thermal treatment of the cement paste so that they can note the possible expansion of the cement in a very short time. We check the stability to ensure that the cements do not contain substances causing, over time, a dangerous expansion.

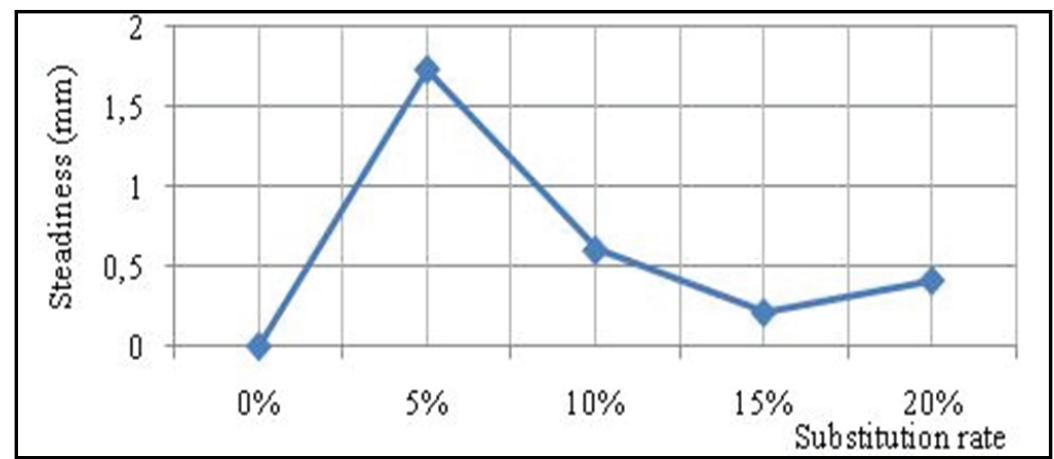

Figure 4: Variation of the steadiness versus the substitution rate

For a specific surface Blaine of marble wastes sand fillers higher than that of cement CEMI, the maximal value is obtained for a substitution rate of $5 \%$, beyond this value, the expansion is a decreasing function and the pointer opening remains always inferior to $10 \mathrm{~mm}$.

\section{EFFECT OF MARBLE WASTE SAND FILLERS ON THE MORTAR CHARACTERISTICS}

\section{Compressive strength}

In the Figure 5, the effect of the substitution rate on the compressive strength for a specific surface Blaine of marble wastes sand fillers higher than that of cement, is indicated. The best compression performances are given by the mortar of $5 \%$ of substitution rate; the variation in short-term (2, 7 days) is less important than the one in medium and long terms (28,90days). The substitution rate increase leads to improve the resistance of the witness mortar till a substitution rate of $5 \%$ for all terms. Pawar and al, (2014), Caré and al, (2002) [14, 5]; found that this percentage was estimated at $10 \%$, the effect is reversed beyond $5 \%$. Between $0 \%$ and $5 \%$ of substitution rate, the $\mathrm{CaO}$ increases; that gives a high compressive strength, the $\mathrm{CaCO} 3$ presence favors the hydration of the C3S from the first moments all the more since the particles are fine (Caré and al, (2002)) [05].

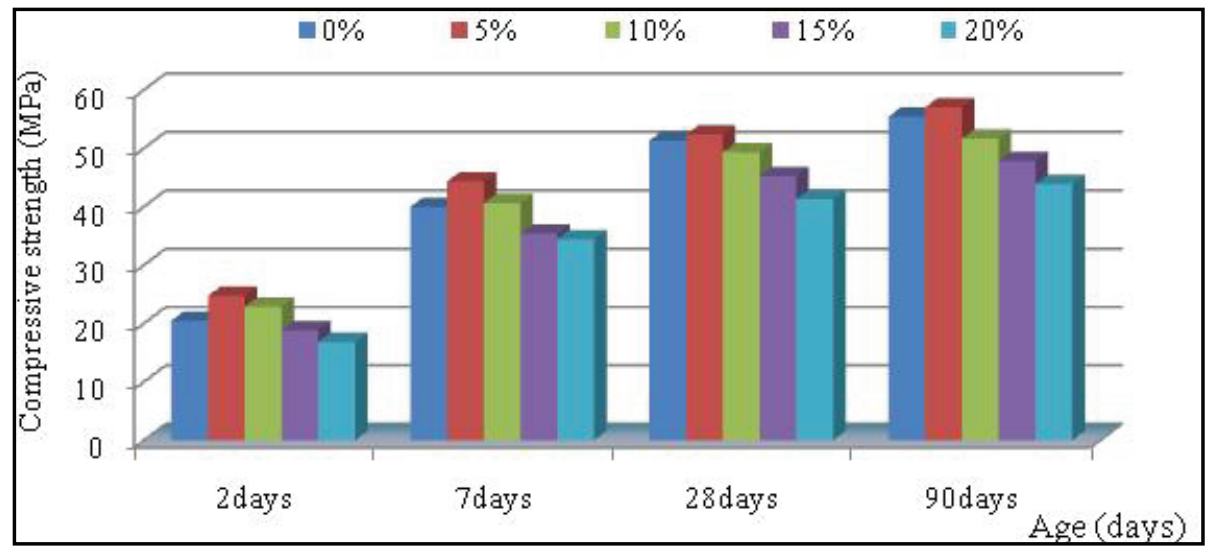

Figure 5: Variation of the compressive strength versus the substitution rate 
Benia, (2011) [04] explains that the specific surface of Blaine is proportional to the speed of the hydraulic reaction and the resistance increase in a short term. The $\mathrm{C}_{2} \mathrm{~S}$ reacts slowly, it confers to cement a resistances lower than the $\mathrm{C}_{3} \mathrm{~S}$, but it develops them in a long-term, that explains the resistances between 28 and 90 days.

\section{Flexural strength}

The best performances are obtained for the formulation of $5 \%$ of substitution rate. The order of mixtures classification is the same for all formulations. For a stronger specific surface of Blaine, the different formulations behavior is the same in medium and long terms, the maximal value is obtained for a substitution rate of $5 \%$ while the minimal value, in accordance with the study executed by Rai and al, (2011) [15] is obtained for a rate of $20 \%$.

\section{Shrinkage}

The Figure 7 shows the shrinkage variation according to the substitution rate.

The shrinkage variation of 2 days according to the substitution rate is insignificant, the addition effect is more remarkable in the seven day, we can also note a shrinkage increase between $0 \%$ and $10 \%$ according to the substitution rate, and the speed is the same in 28 days. The shrinkage increase is proportional to the one of age. The grind fineness is proportional to the speed of hydration reactions and the shrinkage, as approved by Care and al, (2002) [05].

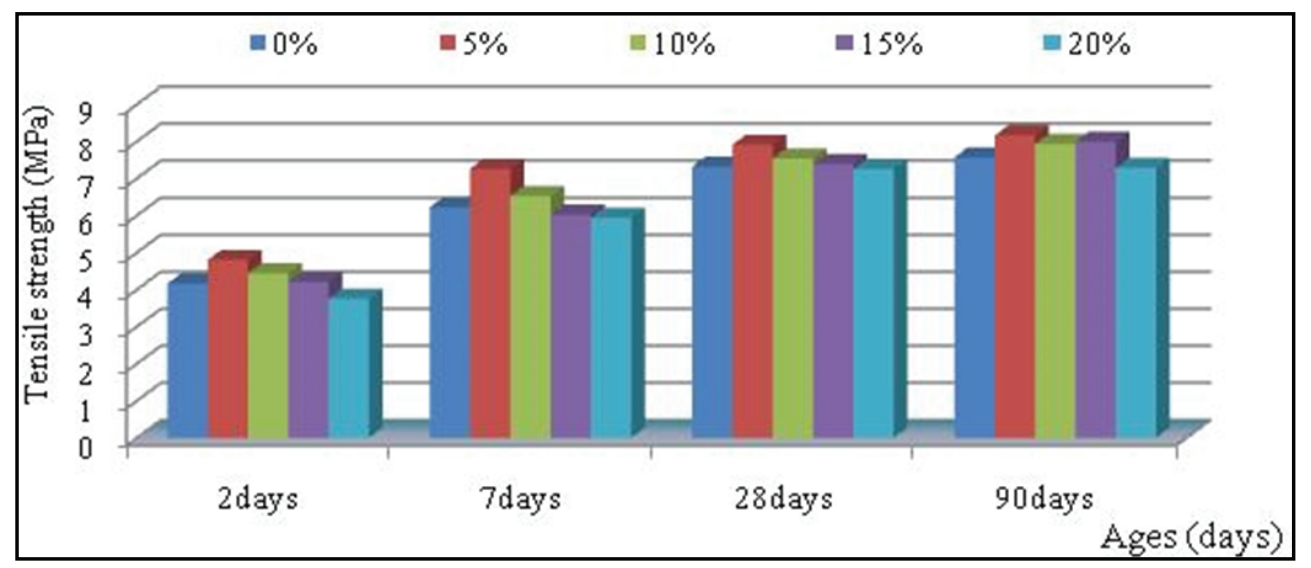

Figure 6: Variation of the tensile strength in flexion versus the substitution rate

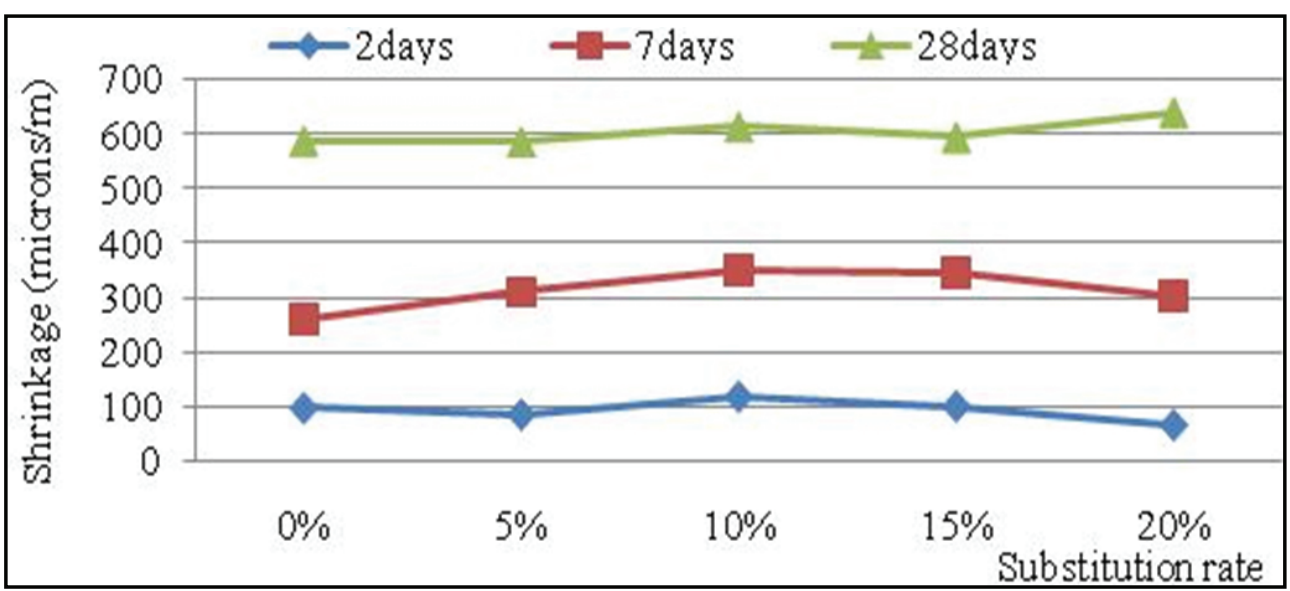

Figure 7: Variation of the shrinkage versus the substitution rate

\section{CONCLUSION}

This work is about the study of the salvage of marble wastes sand as an additive in cement. We conclude, from this study, that:

- The addition of marble wastes sand fillers leads to ameliorate the cement consistency; they decrease the quantity of C3A.

- The stability maximal value is obtained for a substitution rate of $5 \%$.

- Adding marble wastes fillers accelerates, in a short term, the mechanical resistance of mortars, for a higher specific surface of 
Blaine, which implies that the addition of sand marble wastes sand fillers, with high grinding fineness in cement, allows immediate formwork.

- The substitution of clinker by sand marble waste sand fillers gives a good mechanical resistance when finesse is really increased.

- The increase of substitution rate improves the resistance of witness mortar till a substitution rate of $5 \%$ for all terms.

- The best performances, in compressive and tensile strength in flexion, are given by a mortar of $5 \%$ of the substitution rate.

- Introducing sand marble wastes sand fillers leads to increase the cohesion.

- The grind fineness is proportional to the speed of hydration reactions and the shrinkage.

- The addition of $5 \%$ of marble wastes sand fillers permits to move from CEMI cement of the 42.5 class to CEM II of the 52.5 class for a specific surface of Blaine superior to a specific surface Blaine of cement CEMI.

\section{ACKNOWLEDGMENT}

The authors would thank the staff of the Civil Engineering Laboratories in Skikda University, the National school of Algiers for their assistance and support during this study's course and GICA Company (Hdjar EL Soud), for their generous financial support.

\section{REFERENCES}

1) Amritpal Kaur, Er., Rajwinder Singh, Er. (2015). Strength and duriabilty properties of concrete with partial replacement of cement with metakaolin and marble dust, Int. J. Eng. Res. Tech, 04, 1032-1035.

2) Aruntas, H.Y., Guru, M., Dayi, M., Tekin, I. (2010). Utilization of waste marble dust as an additive in cement production, Mater. Des, 31, 4039-4042.

3) Belaidi, A.S.E., Azzouz, L., Kadri, E., Kenai. S. (2012). Effect of natural pozzolana and marble powder on the properties of self-compacting concrete, Const. Build. Mat, 31, 251-257.

4) Benia, M. )2011.( Influence de la surface spécifique des ciments aux ajouts minéraux sur le comportement mécanique du mortier et du béton à base de matériaux locaux, mé- moire de magister, Université de Msila.

5) Caré, S., linder, R., Baroghel Bouny, V., De Larrard, F., Charonnat, Y. (2002). Effet des additions minérales sur les propriétés d'usage du béton-plan d'expérience et analyse statique, LCPC. OA33.

6) Corinaldesi, V., Moriconi, G., Naik, T.R. (2010). Characterization of marble powder for its use in mortar and concrete, Constr. Build. Mater, 24, 113-117.

7) Gurumoorthy, N. (2014). Influence of marble dust as partial replacement of cement in concrete, Int. j. Eng. Res. Tech, 3, 734-740.

8) Hameed, M.S., Sekar, A.S.S. (2009). Properties of green concrete containing quarry rock dust and marble sludge powder as fine aggregate, ARPN. J. of Eng and Appl. Scies, 4, 83-89.

9) Hebhoub, H. (2011(. Recycled aggregate substitution for hydraulic concrete " marble waste», Ph.D. Diss, Skikda University.

10) Hebhoub, H., Belachia, M., Djebien, R. (2013). Introduction of sand marble wastes in the composition of mortar, Struc. Eng. Mec, 49, 491-498.

11) Messan, A. )2006). Contribution à l'étude du comportement au très jeune âge des structures mince en mortier, Ph.D .Diss, Montpellier.

12) Neto, C.S., Campiteli, V.C. (1990). The influence of limestone additions on the rheological properties and water retention value of Portland cement slurries, Car-bonate Additions to Cement, ASTM, STP, 1064, 24-72.

13) Niyazi ugri, K. (2013). Role of construction industry wastes on the properties of mortars, J. Sie. Tech, 3, 109-113.

14) Pawar, M., Dewangan, A. (2014). The significance of partial replacement of cement with waste marble powder, Period. Res, 3, 1-6

15) Rai, B., Naushad, H.K., Abhishek, Kr., Rushad, S.T., Duggal, S.K. (2011). Influence of marble powder/granules in concrete mix, Int .j. civil .Stru. Eng, 1, 827-834.

16) Vuk, T., Tinta, V., Gabrovsek, R., Kaucic, V. (2001). The effects of limestone addition, clinker type and fineness on properties of Portland cement, Cem. Concr. Res, 31, 135- 139.

Paper sent to revision: 18.12.2016

Paper ready for publication: 03.11.2017. 